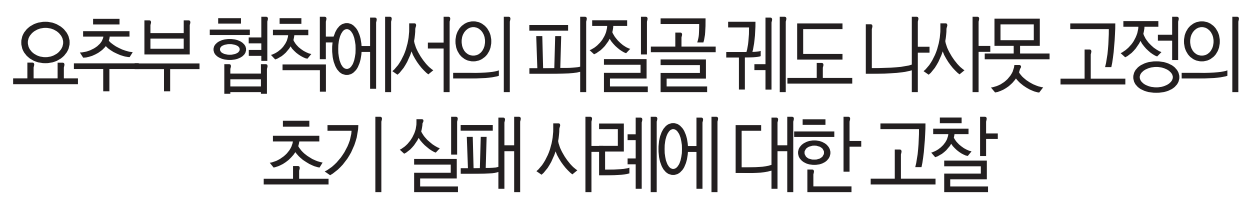

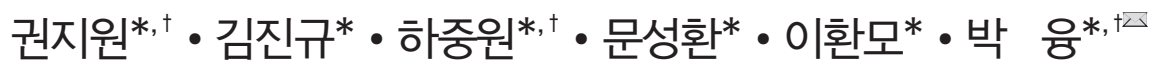

*연세대학교 의과대학 정형외과학교실, ${ }^{\dagger}$ 국민건강보험 일산병원 정형외과

\title{
Early Failure of Cortical-Bone Screw Fixation in the Lumbar Spinal Stenosis
}

\author{
Ji-Won Kwon, M.D. ${ }^{*}$, , Jin-Gyu Kim, M.D.*, Joong-Won Ha, M.D. ${ }^{*},{ }^{\dagger}$, Seong-Hwan Moon, M.D., Ph.D. ${ }^{*}$, \\ Hwan-Mo Lee, M.D., Ph.D.*, and Yung Park, M.D. ${ }^{* \dagger \bowtie}$ \\ ${ }^{*}$ Department of Orthopedic Surgery, Yonsei University College of Medicine, Seoul, \\ ${ }^{\dagger}$ Department of Orthopedic Surgery, National Health Insurance Service Ilsan Hospital, Goyang, Korea
}

Purpose: Pedicle screw insertion has been traditionally used as a surgical treatment for degenerative lumbar spine disease. As an alternative, the cortical-bone trajectory screw allows less invasive posterior lumbar fixation and excellent mechanical stability, as reported in several biomechanical studies. This study evaluated the clinical and radiological results of a case of early failure of cortical-bone screw fixation in posterior fixation and union after posterior decompression.

Materials and Methods: This study examined 311 patients who underwent surgical treatment from 2013 to 2018 using cortical orbital screws as an alternative to traditional pedicle screw fixation for degenerative spinal stenosis and anterior spine dislocation of the lumbar spine. Early fixation failure after surgery was defined as fixation failure, such as loosening, pull-out, and breakage of the screw on computed tomography (CT) and radiographs at a follow-up of six months.

Results: Early fixation failure occurred in 46 out of 311 cases (14.8\%), screw loosening in 46 cases (14.8\%), pull-out in 12 cases (3.9\%), and breakage in four cases (1.3\%). An analysis of the site where the fixation failure occurred revealed the following, L1 in seven cases $(15.2 \%), L 2$ in three cases $(6.5 \%), L 3$ in four cases $(8.7 \%)$, L4 in four cases $(8.7 \%)$, L5 in four cases $(8.7 \%)$, and S1 in 24 cases $(52.2 \%)$. Among the distal cortical bone screws, fixation failures such as loosening, pull-out, and breakage occurred mainly in the $\$ 1$ screws.

Conclusion: Cortical-bone trajectory screw fixation may be an alternative with comparable clinical outcomes or fewer complications compared to conventional pedicle screw fixation. On the other hand, in case with osteoporosis and no anterior support structure particularly at L5-S1 fusion sites were observed to have result of premature fixation failures such as relaxation, pull-out, and breakage.

Key words: early failure, cortical trajectory bone screw, pedicle screws, lumbar spinal stenosis

\section{서 론}

고령화로 인해 전 세계적으로 노인 인구는 급증하는 추세이며 퇴 행성 척추 질환 환자에 대한 수술도 점점 증가하고 있다. 퇴행성

Received June 12, 2019 Revised August 12, 2019 Accepted November 19, 2019 Correspondence to: Yung Park, M.D.

Department of Orthopedic Surgery, National Health Insurance Service Ilsan Hospital, 100 Ilsan-ro, Ilsandong-gu, Goyang 10444, Korea

TEL: +82-31-900-0270 FAX:+82-31-900-0343 E-mail: yungspine@gmail.com ORCID: https://orcid.org/0000-0001-8360-9644
요추 질환 환자에 대한 수술적 치료로 후방 요추부 유합술에 척 추 경 나사못 삽입은 이제 고정적이고 전통적인 장치로 자리매김 해왔다. 하지만 척추 경 나사못 고정은 특히 골밀도가 낮은 환자 에게 나사못 고정력 저하 등의 문제점을 낳게 되었다. ${ }^{1-4)}$ 따라서 
Ji-Won Kwon, et al.

요추부 척추 경 나사못 고정(pedicle screw)보다 향상된 고정을 얻기 위한 새로운 대안 전략으로 Santoni 등은 피질골 궤도 나 사못(cortical-bone trajectory screw) 기술을 소개했다. 그들의 사체 연구는 피질골 궤도 나사못이 전통적인 척추 경 나사못에 비해 일축성 나사못 철수 하중이 $30 \%$ 증가한 것을 보여주었다. 또한 생체실험 연구결과 피질골 궤도 나사못은 기존 척추 경 나 사못보다 1.71배 더 큰 삽입 토크를 나타냈다. ${ }^{5-7)}$ 이를 비롯한 몇 몇의 생체 역학 연구는 피질골 궤도 나사못의 유리한 기계적 성 질을 보여주었고 또한 내측 출발점을 통한 나사못 삽입은 상부면 관절의 노출을 제한하고 근육 해부 및 이로 인한 손상을 줄임으 로써 덜 침습적인 후방 요추부 고정을 가능하게 하여 척추 경 나 사못보다 더 우수한 결과를 도출할 수 있는 방법으로 주목을 받 아왔다. ${ }^{8-10)}$ 하지만 피질골 궤도 나사못 고정을 이용한 후방 추체 간 유합술(posterior lumbar interbody fusion) 및 후외측 추체 간 유합술(posterolateral fusion)의 수술 결과와 관련하여 임상 적 결과와 관련된 논문은 거의 없다. ${ }^{8,10)}$ 따라서 본 연구의 목적은 후방 감압술 후 후방 추체간 유합술 및 후외측 추체간 유합술을 시행한 환자에 있어 피질골 나사못 고정술의 초기 실패에 관한 사례의 임상적 결과 및 방사선적 결과를 나열하여 초기 실패 사 례의 공통점에 대해 고찰하고자 한다.

\section{대상 및 방법}

\section{1. 대상}

2013년 4월부터 2018년 6월까지 국민건강보험 일산병원에서 요추부 퇴행성 질환(척추관 협착증, 척추 전방 전위증)으로 진단 후 피질골 궤도 나사못 고정을 사용하여 후방 감압술 및 후외측/ 후방 추체간 유합술을 받은 총 311예를 대상으로 후향적으로 분 석하였다. 인접 분절 퇴행성 변화에 의한 재수술이거나 전신 자
가면역질환, 낙상 등으로 인한 인접부위 압박성 골절, 전이성 골 종양에 의해 발생한 병적 골절은 연구대상에서 제외하였다.

본 연구는 국민건강보험 일산병원 임상연구윤리위원회(Institutional Review Board, IRB)의 승인을 받아 시행되었다(IRB no. 2018-04-024).

\section{2. 치료 방법 및 추시 방법}

수술은 복와위에서 후방으로 접근하여 감압술(후궁판, 황색인대, 추간판 및 후관절 절제술) 후 피질골 나사못 고정을 사용하여 후 방 감압술 및 후외측/후방 추체간 유합술을 시행하였다. 수술 후 3 개월간 흥요천추 보조기를 착용시켰으며 수술 후 6주, 3 개월, 6 개월, 1 년, 2 년 간격으로 외래 추시관찰을 하였다. 수술 후 6개월 까지를 수술 후 초기라는 기간 설정 및 정의를 하였으며 각각 외 래 추시마다 요추부 방사선 사진을 시행하였다. 수술 후 6 개월째 외래 추시 때에는 추가적으로 요추부 컴퓨터 단층촬영(computed tomography, CT)을 시행하였다.

\section{3. 연구 방법}

나사못 고정술 실패(fixation failure)는 3개의 군으로 분류하였 으며 이완(screw loosening), 이탈(pull-out), 파손(breakage)으 로 다음과 같다. 이완은 방사선 사진 및 요추부 CT검사상 방사 선투과(radiolucent)성의 달무리징후(halo sign)가 보이는 것으 로 정의하였다. ${ }^{8)}$ 이탈은 수술적 치료 시 삽입되었던 나사못의 위 치가 외래 추시를 시행함에 있어서 후방으로 전위가 $2 \mathrm{~mm}$ 이상 일어난 것으로 정의하였다. ${ }^{8)}$ 파손은 외래 추시상에서 나사못의 방사선비투과성 연속성(radiopaque continuity)이 소실된 상 태로 정의하였다. 수술 후 6 개월 이내에 3 가지의 방사선 사진을 사용한 형태학적 고정 실패가 발생한 경우를 수술 후 초기 나사 못 고정술 실패로 정의하였고 방사선 사진을 통해 각 3 개의 군으
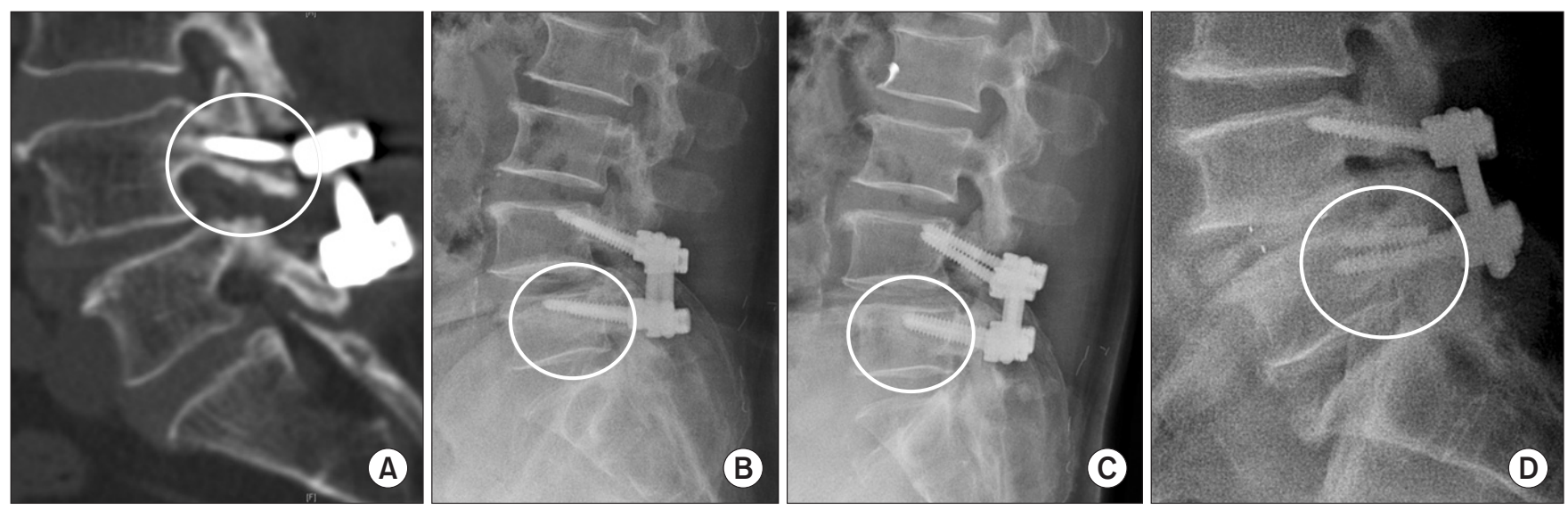

Figure 1. (A) Represents screw loosening with peri-screw halo radiolucent findings. (B) Immediate postoperative lateral X-ray. (C) Screw pull-out with a clearance over $2 \mathrm{~mm}$. (D) Screw breakage. 
로 분류를 시행하였으며 중복 측정도 해당 조건 및 정의를 만족 했을 시 가능하게 적용하였다(Fig. 1). 또한 평균 나이, 성별, 골밀 도 검사(bone mineral density, $\mathrm{BMD}$ ), 체질량지수(body mass index, BMI), 유합 마디 숫자, 유합 마디 부위, 추체간 유합술 (interbody fusion) 시행 여부, 방사선 사진상에서 삽입된 피질 골 궤도 나사못의 궤적(trajectory)을 반영하는 cephalad 각도, lateral 각도를 측정하여 후향적으로 분석하였다. ${ }^{5,11)}$ Lateral 각 도는 축 방향에서 측정 된 내측 대 측면 피질골 궤도 나사못 궤도 와 가시돌기의 장축 사이의 각도로 정의하였으며 cephalad 각도 는 시상면상에서 피질골 궤도 나사못의 각도와 삽입된 척추체의 상부 골단판 선과의 각도로 정의하였다(Fig. 2). 통계 분석에는 고 정술 실패군에 대해 앞서 언급한 지표들의 평균치 분석을 시행하 였다.

\section{결 과}

추시 중 조기 고정 실패(early fixation failure)가 발생한 경우 는 총 311예 중 46예(14.8\%)였고 이완은 46예(14.8\%), 이탈은 12예(3.9\%), 파손(breakage)은 4예(1.3\%)를 보였다. 전체 환자 중 남성은 14 명(30.4\%), 여성은 32명(69.6\%)이었으며 평균 연령 은 $68.1 \pm 10.4$ 세, 남성은 $61.6 \pm 14$ 세, 여성은 $71.8 \pm 5.5$ 세였다. $\mathrm{BMI}$ 는 평균 $24.92 \pm 4.56$ 였다. 류마티스 관절염과 통풍 등의 염 증성 질환을 동반한 환자 6명(13.0\%), 당뇨 및 갑상선 등의 내분 비내과 질환을 동반한 환자 10 명(21.7\%), 심혈관계 질환 및 폐질 환 등의 내과 질환을 동반한 환자 24명(52.2\%), 기저질환이 없는 환자 16명(34.8\%)을 나타내었다. 흡연력은 남성에서만 나타났으 며, 8명(17.4\%) 소견을 보였다. $\mathrm{BMD}$ 는 척추에서 T score가 - 2.1 \pm 1.1 , 골반에서는 $\mathrm{T}$ score가 $-1.7 \pm 0.7$ 로 나타났다. 수술시간 (operating time)은 평균 274.5 \pm 62.1 분, 예상실혈량(expected blood loss)은 평균 $528 \pm 424.3 \mathrm{ml}$ 이었다. 추체간 유합술은 46
예 중에 총 16예(34.8\%)에서 시행하였다. 조기 고정 실패가 일 어난 마디는 L1이 7예(15.2\%), L2가 3예(6.5\%), L3가 4예(8.7\%), L4가 4예(8.7\%), L5가 4예(8.7\%), 그리고 S1이 24예(52.2\%)였 다. 유합부위의 피질골 궤도 나사못에 고정 실패가 흥요추 유합 (lumbosacral fusion), 즉 S1 screws에서 상대적으로 많은 비율 로 이완 및 이탈, 파손 등의 고정 실패가 일어났다. 방사선 사진상 피질골 궤도 나사못의 궤적을 반영하는 cephalad 각도, lateral 각도는 각각 $14.36^{\circ} \pm 7.75^{\circ}, 5.31^{\circ} \pm 6.80^{\circ}$ 였다(Table 1).

\section{고 찰}

퇴행성 요추부 질환의 수술적 치료의 전통적 기구로서 사용되 는 척추 경 나사못은 몇몇의 한계점을 가지고 있다. 특히 골다공 증 환자에서 발생되는 나사못 이완 및 이탈이 바로 그것인데 피 질골 궤도 나사못의 출현은 이러한 단점을 완화하는 데 도움이 될 수 있다고 알려져 있다. 그리고 피질골 궤도 나사못의 시작점 은 척추 경 나사못보다 후관절 기준으로 내측에 위치하기 때문 에 골막하 박리시 후관절 노출 및 척추 주위(paraspinal) 근육의 손상을 감소시키며, 나사못 주행경로가 척추 경 나사못보다 이론 적으로 신경 손상의 위험을 감소시킬 수 있다. ${ }^{310,12)}$ 생체 역학적 연구들이 피질골 궤도 나사못의 우수성을 보고했는데, Santoni 등 ${ }^{3)}$ 은 사체 모형에서 척추 경 나사못과 비교하여 일축성 나사못 철수 하중이 $30 \%$ 증가하는 것으로 나타났다. 또한 Baluch 등 ${ }^{13)}$ 이 시행한 생체실험 연구결과 피질골 궤도 나사못은 기존 척추 경 나사못보다 1.71 배 더 큰 삽입 토크를 나타냈다. 하지만 피질 골 궤도 나사못을 사용한 수술적 치료의 임상적 및 방사선 결과 에 대한 연구 보고는 많이 없다. 최근에 보고된 바로는 Glennie 등이이 2015년 퇴행성 요추부 질환에서 피질골 궤도 나사못을 사 용하여 수술적 치료를 시행한 12 명의 환자에서 1 년 추시한 후향 성 연구가 그것이다. 12 명 중 5 명의 환자에서 나사못 이완 및 이

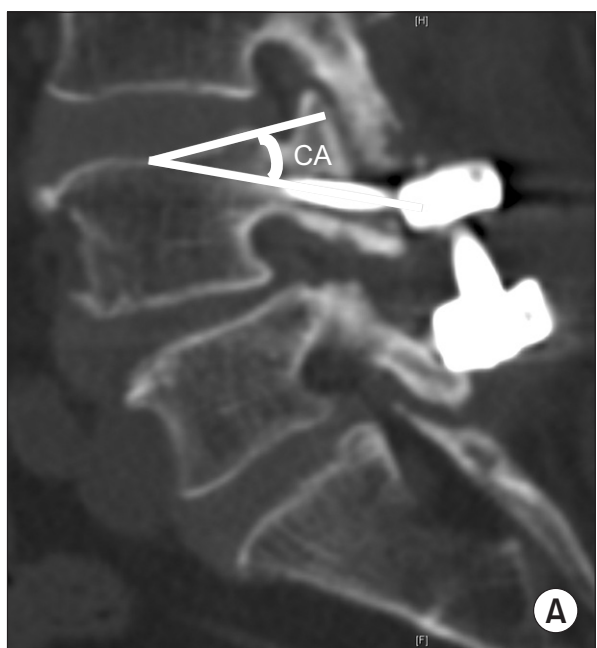

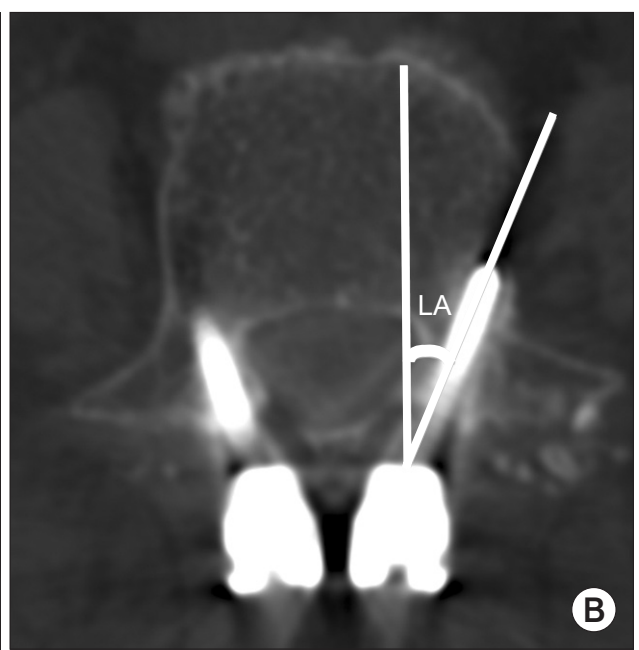

Figure 2. $(A, B)$ Measurements of the cortical-bone trajectory. CA, cephalad angle; LA, lateral angle. 
Ji-Won Kwon, et al.

Table 1. Characteristics of the Early Failure Group $(n=46)$

\begin{tabular}{lc}
\multicolumn{1}{c}{ Variable } & Early failure group \\
Sex & $14(30.4)$ \\
Male & $32(69.6)$ \\
Female & \\
Mean age (yr) & $61.6 \pm 14$ \\
Male & $71.8 \pm 5.5$ \\
Female & $24.9 \pm 4.6$ \\
BMl (kg/m²) & \\
Smoking history* & \\
Male & $8(17.4)$ \\
Female & $0(0)$ \\
BMD (T-score) & \\
Spine & $-2.1 \pm 1.1$ \\
Femur & $-1.7 \pm 0.7$ \\
No. of segments operated on & \\
1 & $10(21.7)$ \\
2 & $14(30.4)$ \\
3 & $16(34.8)$ \\
4 & $6(13.0)$ \\
Existence of interbody fusion & \\
Yes & $16(34.8)$ \\
No & $30(65.2)$ \\
Location of the screw where early failure occurred \\
L1 \\
L2 \\
L3 \\
L4 \\
L5 & $7(15.2)$ \\
S1 & $3(6.5)$ \\
\hline & $4(8.7)$ \\
& $4(8.7)$ \\
& $4(8.7)$ \\
& $24(52.2)$ \\
\hline
\end{tabular}

Values are presented as number (\%) or mean \pm standard deviation. ${ }^{*}$ The result of a history taking of whether or not current smoking. BMI, body mass index; BMD, bone mineral density.

탈 소견을 보였으며 이 중 3명은 추체간 유합술을 시행하지 않 았다. 이에 Glennie 등은 피질골 궤도 나사못을 사용한 수술적 치료시 추체간 유합술을 사용을 권장했었다. 또한 Sakaura 등 ${ }^{14)}$ 이 2018년 보고한 환자 대조군 연구에 따르면 추체간 유합술에 서 피질골 궤도 나사못을 사용한 군이 척추 경 나사못 고정을 시 행한 군에 비해 임상적 증상 호전이 비교할 만하다고 보고하였 다. ${ }^{14)}$ 이처럼 임상적 연구결과에 대한 보고들이 나오는 상태에서 본 연구는 피질골 궤도 나사못의 조기 고정 실패 사례를 통해 이 러한 합병증으로 이환되는 사례의 공통점에 대해서 파악해보고 자 했다. 본 연구에서는 조기 고정 실패 사례를 분석했을 시 전방
지지력 결손이 예상되는 조건, 즉 추체간 유합술을 시행하지 아 니한 군의 비율이 더 높았다. 또한 조기 고정 실패 사례에서 요천 추부(lumbosacral) 유합술 시행, 2분절 이상의 다분절 유합술, 환자의 기저질환상 낮은 골밀도 수치(low BMD T-score) 및 높 은 체질량지수(high $\mathrm{BMI})$ 의 비중이 더 큰 것을 관찰할 수 있었 다. 이는 Kowalski 등히이 발표한 고정되지 않은 모멘트 암 외팔 보(nonfixed moment arm cantilever beam) 모형으로 생각해 볼 수 있겠다. ${ }^{16)}$ 굽힘 모멘트가 척추에 가해지는 경우는 거의 없 기 때문에 축방향 하중을 견딜 수 있는 본질적인 기능이 거의 없 으므로 척추가 손상되지 않았거나 하중지지 기능이 있는 다른 구 조물 즉, 추체간 골이식편이 함께 사용되어야 한다는 것이다. 따 라서 전방 지지력이 충분하지 못한 요천추부에서 발산형(divergent) 궤도가 아닌 피질골 궤도 나사못의 주행경로는 고정되지 않은 모멘트 암 외팔보 모형에서 척추가 굴곡할 때 장력대 강선 고정(tension band fixation) 기능을 할 수 없어 나사못 이탈 저 항이 매우 약해질 수 있게 된다. 따라서 본 연구에서 조기 고정 실 패를 보인 환자군에 대한 분석을 통해 전방 지지 구조를 할 수 있 는 구조적 지지와 원위 나사못을 일반적으로 피질골 궤도 나사못 으로 시행하는 경우, 평균 $30 \mathrm{~mm}$ 의 길이보다 더 길게 삽입하는 방안과 그게 여의치 않다면 차라리 원위 부위에 척추 경 나사못 을 삽입하는 것이 고정력 향상에 중요한 결과를 나을 것으로 생 각된다. ${ }^{9,12)}$

이 연구는 제한점을 가지고 있다. 이 연구의 설정은 피질골 궤 도 나사못으로 수술적 치료를 받은 환자에 있어 조기 실패 고정 사례가 있는 환자들을 추출하여 이들의 방사선, 임상학적 수치 및 결과를 공통화하였기 때문에 실패군에서 공통점을 보인 요인 에 대한 나열이며 이에 대한 고찰에 의의를 두어야 할 것으로 보 인다. 추후 본 연구에서 제시한 가설을 통계적으로 뒷받침하기 위해서 환자-대조군 연구나 생체 역학 연구 및 이중눈가림연구 가 필요할 수 있겠다.

\section{결 론}

피질골 궤도 나사못 고정은 척추 경 나사못 고정과 비교했을 때 동등한 임상 결과 또는 적은 합병증을 나타낼 수 있는 하나의 대 안이 될 수 있다. 골다공증이 있거나 특히 L5-S1 유합부위에서 전방지지구조가 되지 않는 조건일 때 이완, 이탈, 파손 등의 조기 고정 실패가 나타나는 결과가 있었다.

\section{CONFLICTS OF INTEREST}

The authors have nothing to disclose. 
Early Failure of Cortical-Bone Screw Fixation

\section{ORCID}

Ji-Won Kwon, https://orcid.org/0000-0003-4880-5310

Jin-Gyu Kim, https://orcid.org/0000-0002-5971-3019

Joong-Won Ha, https://orcid.org/0000-0002-8260-2958

Seong-Hwan Moon, https://orcid.org/0000-0003-4302-1920

Hwan-Mo Lee, https://orcid.org/0000-0002-5405-3832

Yung Park, https://orcid.org/0000-0001-8360-9644

\section{REFERENCES}

1. Chao CK, Hsu CC, Wang JL, Lin J. Increasing bending strength and pullout strength in conical pedicle screws: biomechanical tests and finite element analyses. J Spinal Disord Tech. 2008;21:130-8.

2. Krag MH, Beynnon BD, Pope MH, DeCoster TA. Depth of insertion of transpedicular vertebral screws into human vertebrae: effect upon screw-vertebra interface strength. J Spinal Disord. 1988;1:287-94.

3. Santoni BG, Hynes RA, McGilvray KC, et al. Cortical bone trajectory for lumbar pedicle screws. Spine J. 2009;9:366-73.

4. Skinner R, Maybee J, Transfeldt E, Venter R, Chalmers W. Experimental pullout testing and comparison of variables in transpedicular screw fixation. A biomechanical study. Spine (Phila Pa 1976). 1990;15:195-201.

5. Gao H, Zhang R, Jia C, et al. Novel placement of cortical bone trajectory screws in the lumbar spine: a radiographic and cadaveric study. Clin Spine Surg. 2018;31:E329-36.

6. Matsukawa K, Yato Y, Kato T, Imabayashi H, Asazuma T, Nemoto K. In vivo analysis of insertional torque during pedicle screwing using cortical bone trajectory technique. Spine (Phila Pa 1976). 2014;39:E240-5.

7. Yuan Q, Han X, Han X, He D, Liu B, Tian W. Krag versus Caudad trajectory technique for pedicle screw insertion in osteoporotic vertebrae: biomechanical comparison and anal- ysis. Spine (Phila Pa 1976). 2014;39:B27-35.

8. Glennie RA, Dea N, Kwon BK, Street JT. Early clinical results with cortically based pedicle screw trajectory for fusion of the degenerative lumbar spine. J Clin Neurosci. 2015;22:972-5.

9. Hoffman H, Verhave B, Jalal MS, Beutler T, Galgano MA, Chin LS. Comparison of cortical bone trajectory screw placement using the midline lumbar fusion technique to traditional pedicle screws: a case-control study. Int J Spine Surg. 2019;13:33-8.

10. Keorochana G, Pairuchvej S, Trathitephun W, Arirachakaran A, Predeeprompan P, Kongtharvonskul J. Comparative outcomes of cortical screw trajectory fixation and pedicle screw fixation in lumbar spinal fusion: systematic review and meta-analysis. World Neurosurg. 2017;102:340-9.

11. Rodriguez A, Neal MT, Liu A, Somasundaram A, Hsu W, Branch CL Jr. Novel placement of cortical bone trajectory screws in previously instrumented pedicles for adjacent-segment lumbar disease using CT image-guided navigation. Neurosurg Focus. 2014;36:E9.

12. Kaye ID, Prasad SK, Vaccaro AR, Hilibrand AS. The cortical bone trajectory for pedicle screw insertion. JBJS Rev. 2017;5:e13.

13. Baluch DA, Patel AA, Lullo B, et al. Effect of physiological loads on cortical and traditional pedicle screw fixation. Spine (Phila Pa 1976). 2014;39:E1297-302.

14. Sakaura H, Miwa T, Yamashita T, Kuroda Y, Ohwada T. Cortical bone trajectory screw fixation versus traditional pedicle screw fixation for 2-level posterior lumbar interbody fusion: comparison of surgical outcomes for 2-level degenerative lumbar spondylolisthesis. J Neurosurg Spine. 2018;28:57-62.

15. Kowalski RJ, Ferrara LA, Benzel EC. Biomechanics of bone fusion. Neurosurg Focus. 2001;10:E2.

16. Larson SJ. Biomechanics of spine stabilization: principles and clinical practice. Neurosurgery. 1996;38:226-30. 


\section{요추부협착에서의피질골궤도나사못 고정의 초기실패시례에대한 고찰

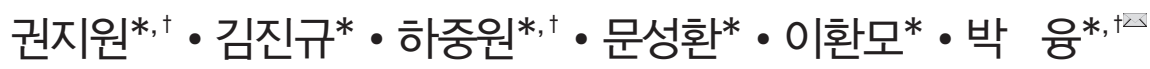 *연세대학교 의과대학 정형외과학교실, ${ }^{\dagger}$ 국민건강보험 일산병원 정형외과}

목적: 퇴행성 요추부 척추 질환에 대한 수술적 치료로 척추 경 나사못(pedicle screw) 삽입술이 전통적으로 사용되어왔다. 이에 대 한 대안으로 제시된 피질골 궤도 나사못(cortical-bone trajectory screw)은 덜 침습적인 후방 요추부 고정이 가능한 점과 몇몇의 생체 역학 연구에서 보고한 우수한 기계적 안정성을 장점으로 가지고 있다. 본 연구의 목적은 후방 감압술 후 후방 고정술 및 유합 을 시행한 환자에 있어 피질골 궤도 나사못 고정술의 초기 실패에 관한 사례의 임상적 및 방사선적 결과를 알아보고자 함에 있다. 대상 및 방법: 요추의 퇴행성 척추 협착 및 척추 전방 전위에 대한 전통적인 척추 경 나사못 고정을 대안하여 피질골 궤도 나사못 을 사용하여 2013년부터 2018년까지 수술적 치료를 시행한 311명의 환자를 대상으로 하였다. 수술 후 조기 고정 실패는 수술 후 6개월째, 외래 추시에서 시행한 컴퓨터 단층촬영(computed tomography) 및 방사선 사진상 나사못의 이완, 이탈 및 파손과 같은 고정 실패가 일어날 시로 정의하였다.

결과: 조기 고정 실패는 311예 중 46예(14.8\%), 나사못 이완이 46예(14.8\%), 이탈이 12예(3.9\%), 파손이 4예(1.3\%)에서 발생하였 다. 해당 고정 실패가 일어난 부위 분석 시, L1이 7예(15.2\%), L2가 3예(6.5\%), L3가 4예(8.7\%), L4가 4예(8.7\%), L5가 4예(8.7\%), 그리고 S1이 24예(52.2\%)였다. 주로 말단 피질골 궤도 나사못 중에서도 S1 나사못에서 이완, 이탈 및 파손과 같은 고정 실패가 주 로 발생하였다.

결론: 피질골 궤도 나사못 고정은 기존의 척추 경 나사못 고정과 비교했을 때 동등한 임상 결과 또는 적은 합병증을 나타낼 수 있는 하나의 대안이 될 수 있으나 골다공증이 있거나 특히 L5-S1 유합부위에서 전방지지구조가 되지 않는 조건일 때, 이완, 이탈, 파손 등의 조기 고정 실패가 나타나는 결과가 있었다.

색인단어: 조기 실패, 피질골 궤도 나사못, 척추 경 나사못, 요추부 척추 협착

접수일 2019년 6월 12일 수정일 2019년 8월 12일 게재확정일 2019년 11월 19일

책임저자 박 융

10444 , 고양시 일산동구 일산로 100 , 국민건강보험 일산병원 정형외과

TEL 031-900-0270, FAX 031-900-0343, E-mail yungspine@gmail.com, 0RCID https://orcid.org/0000-0001-8360-9644 